\title{
Role of the contrast-enhanced ultrasoud in the diagnosis of HCC in cirrhotic liver
}

\author{
Francesco Loria', Antonello Parlati', Giuseppe Loria', Luciano Frosina ${ }^{2}$, Giuseppe Crea ${ }^{3}$, Salvatore \\ Basile ${ }^{3}$, Caterina Alessio', Giuseppe Di Leo ${ }^{1}$, Adele De Caridi', Vittorio Maschio', Nicola Zizzi', Orazio \\ Trapuzzano', Salvatore Giuseppe Galea ${ }^{1}$
}

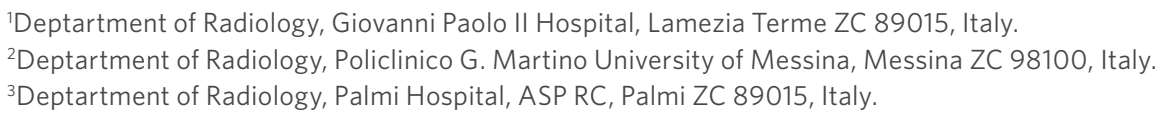

Correspondence to: Dr. Francesco Loria, Deptartment of Radiology, Giovanni Paolo Il Hospital Lamezia Terme, Lamezia Terme ZC 89015, Italy. E-mail: francescoloria956@alice.it

How to cite this article: Loria F, Parlati A, Loria G, Frosina L, Crea G, Basile S, Alessio C, Di Leo G, De Caridi A, Maschio V, Zizzi N, Trapuzzano O, Galea SG. Role of the contrast-enhanced ultrasoud in the diagnosis of HCC in cirrhotic liver. Hepatoma Res 2018;4:59. http://dx.doi.org/10.20517/2394-5079.2018.75

Received: 8 Jun 2018 First Decision: 1 Aug 2018 Revised: 28 Aug 2018 Accepted: 29 Aug 2018 Published: 28 Sep 2018

Science Editor: Guang-Wen Cao Copy Editor: Yuan-Li Wang Production Editor: Zhong-Yu Guo

\begin{abstract}
The development of second generation ultrasound (US) contrast-medium and specific imaging techniques with dedicated softwares, allows to observe the liver perfusion in real time, becoming an useful and less invasive method to describe precisely the vascularization of hepatic lesions. This significantly increased the ability of US to detect and characterize focal liver lesions. The aim of this review article is to evaluate the role of contrast enhancement US in the diagnosis of hepatocellular carcinoma in cirrhotic liver, with reference to the guidelines of American Association for the Study of Liver Diseases, European Association for the Study of the Liver and European Federation of Societies for Ultrasound in Medicine and Biology.
\end{abstract}

Keywords: Contrast-enhanced ultrasound, hepato-cellular carcinoma, cirrhotic liver

\section{INTRODUCTION}

Hepatocellular carcinoma (HCC) is the most common malignancy of the liver. Ultrasound (US) examination and measurement of serum levels of alpha-fetoprotein (AFP) represent the most common screening method for $\mathrm{HCC}^{[1]}$.

However, the conventional grayscale US and Color-Power Doppler US show limited ability in characterizing

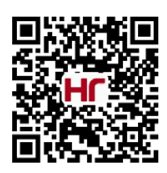


liver tumors ${ }^{[2-5]}$ and the sensitivity of these biomarkers in the detection of early HCC or small lesions is limited. AFP levels may also be elevated in other malignancies, such as intrahepatic-cholangiocarcinoma (ICC) or colon cancer, as well as during follow-up of chronic viral hepatitis ${ }^{[6]}$.

The study of vascularization within the nodule in focal liver lesions (FLLs) in a cirrhotic liver is considered to be useful in identification and characterization with various imaging techniques ${ }^{[7-16]}$.

With the development of a second generation of US contrast-agent and real-time contrast-specific techniques, contrast-enhanced ultrasound (CEUS) has been widely used in clinical studies and has greatly improved the diagnostic ability of US in identification of FLLs ${ }^{[16-21]}$.

\section{CONSTRAST MEDIA}

Currently, there are four US contrast agents for liver studies: (1) SonoVue (BraccoSpA, Milan Italy introduced in 2001) that consists of stabilized gaseous microbubbles (sulfur hexafluoride) equal to or smaller than red blood cells, with a diameter of less than $7 \mu \mathrm{m}$, stabilized inside a phospholipid shell; (2) Definity (Lantheus Medical, Billerica, MA, USA, introduced in 2001) consists of stabilized microbubbles of perflutren with a lipid shell; (3) Optison (GE Healthcare) consists of stabilized microbubbles of human serum albumin with octofluoropropane; and (4) Sonazoid (Daiichi-Sankyo, GE Tokio, Japan, introduced in 2007) that consists of stabilized gaseous microbubbles (perfluorobutane) with phospholipid shell (hydrogenated egg phosphatidyl serine) ${ }^{[22]}$.

Definity and Optison have been authorized only in USA and Canada for cardiological imaging; in Canada Definity is used also for other body districts. Sonazoid is used only in Japan and SonoVue in Europe and China. In Europe only Optison is used for cardiological imaging.

In consideration of what previously said, in our article we will exclusively refer to SonoVue, the only US contrast medium authorized in Europe for the study of FLLs.

\section{Basic of CEUS}

The contrast media SonoVue consists of microbubbles of stabilized phospholipids containing sulphure-hexafluoride, with the same or inferior dimension of red blood cells (diameter inferior to $7 \mu \mathrm{m}$ ). Due to their small size the microbubbles act as an "blood pool agent" and allow the real time study of the macro- and microvascular circulation for several minutes ${ }^{[23-25]}$.

The interaction between the microbubble blood pool and the incident US beam is the key to understand the mechanism of action of the US contrast agent and its clinical applications. When the microbubbles are hit by the US beam at low mechanical index (MI) $(<100 \mathrm{kPa}-\mathrm{MI}<0.1)$, they are exposed to a low-level positive (compression) and negative (dilatation) sound pressure. In this case the microbubbles behave in a linear way as simple reflectors, without breaking. In this way a linear reflection phenomenon is generated which results in a wide reinforcement of the scattering coming from the circulating blood. Increasing the acoustic intensity of the incident beam (MI between 0.1 and 1), the oscillation becomes more intense and asymmetric and the physical behavior of the microbubbles becomes non-linear. Because of non-linear reflection, if the microbubbles are hit by an acoustic beam with this intensity, they generate a reinforcement of the fundamental signal and a harmonic energy.

The non linear behavior of the microbubbles shows itself in a way not dissimilar to stationary tissue. The main advantage that derives from the use of US contrast media is that the amount of the signal coming from the second harmonic, which originates from the microbubbles, is of a length greater than that coming from stationary tissues. 
Therefore, thanks to the use of specific software, the linear signals are deleted from the tissues and the images are formed only thanks to the non-linear signals coming from the microbubbles. The use of these more powerful acoustic waves, however, causes the breaking of part of the micro-bubbles. To minimize this phenomenon, we have chosen to work at low mechanical indices. This study technique allows to cancel the signal coming from the tissues and to have pure images coming exclusively from the microbubbles ${ }^{[25-29]}$.

Although the correct setting of the US scanner and the scanning techniques are important for avoiding artifacts ${ }^{[30]}$, MI and inadequate gain are the two main causes of error in the visualization of the signals coming from the tissues.

\section{PROTOCOL OF SURVEILLANCE OF HCC}

In our institute, we use a HCC surveillance protocol in patients with cirrhosis, based on the six-monthly dosing of alpha-fetus protein serum levels and on the execution of a six-monthly hepatic US examination in patients in the Child Pugh class A and B. In patients in the Child Pugh class C, the US can be also performed every three months.

\section{DIAGNOSIS OF HCC}

\section{Baseline us}

HCC typically appear as hypoechoic compared to the surrounding hepatic parenchyma. It can also appear as isoechoic, hyperechoic or with mixed echogenicity, with a typical characteristic of nodule in nodule. About $50 \%$ of HCC can appear as a nodule with peripheral hypoechoic halo ${ }^{[22]}$. Both the conventional Color-Doppler and the Power-Doppler US have a limited ability to describe intralesional vascularization, because they are insensitive to slow and deep blood flows ${ }^{[31,32]}$. Generally the Doppler HCC pattern is characterized by an arterial vascularization with a basket pattern due to thin blood vessels that surrounds the nodule $e^{[11,22,33]}$.

\section{CEUS procedures}

Before starting the CEUS evaluation, it is mandatory to perform an evaluation in B-mode; in particular it is necessary to analyze the site, the size, dimensions, echogenicity of the lesion and its relationship with the other structures. An evaluation of the vascular pattern of the lesion in Color-Doppler is useful to define the eventual presence of central or peripheral vascular vessels. Once the target lesion has been identified, the specific mode of imaging must be selected for the contrast with a low MI. SonoVue is injected into the antecubital vein with a bolus, followed by a bolus flash of a solution of $10 \mathrm{~mL}$ of sodium chloride. To avoid destroying the microbubbles during the injection, the calibre of the needle must not be less than 20 gauge ${ }^{[22]}$. The target lesion and the surrounding parenchyma are observed for 5-10 min in real time and registered in a video clip. The arterial phase is defined as 0-30 s from the injection, the portal phase 31-75 and the late phase from $75-180 \mathrm{~s}$ up to $10 \min ^{[31]}$.

\section{CEUS}

The most common appearance in cirrhotic liver of HCC is an hyper-arterial enhancement compared to the surrounding hepatic tissue [Figure 1], which is found in $93.5 \%-97 \%$ of cases $^{[31,33-38]}$ and generally appear homogeneous and intense. In the nodules that have diameters larger than $2 \mathrm{~cm}$, hyper-enhancement can also be non-homogenous because of the area of necrosis within the lesion [Figure 2]. A slight peripheral enhancement is found in 5 (34.6\%) of cases of HCC; it can represent the tumor capsule [Figure 3] or blood vessel around the lesion ${ }^{[31,33-39]}$. In the majority of cases HCC shows a precocious enhancement compared to the surrounding tissue, in particular, the rates of detection of the hyper-enhancement in lesions $<1.0 \mathrm{~cm}, 1.0-2.0 \mathrm{~cm}$ and $2.0-3.0$ $\mathrm{cm}$ are respectively $67 \%, 83 \%-88 \%$ and $92 \%-100 \%{ }^{[3,31,36-40]}$ [Table 1]. Furthermore other lesions like dysplastic nodules and hyper-vascularized hemangioma can have the same contrast enhancement pattern ${ }^{[4]}$. 

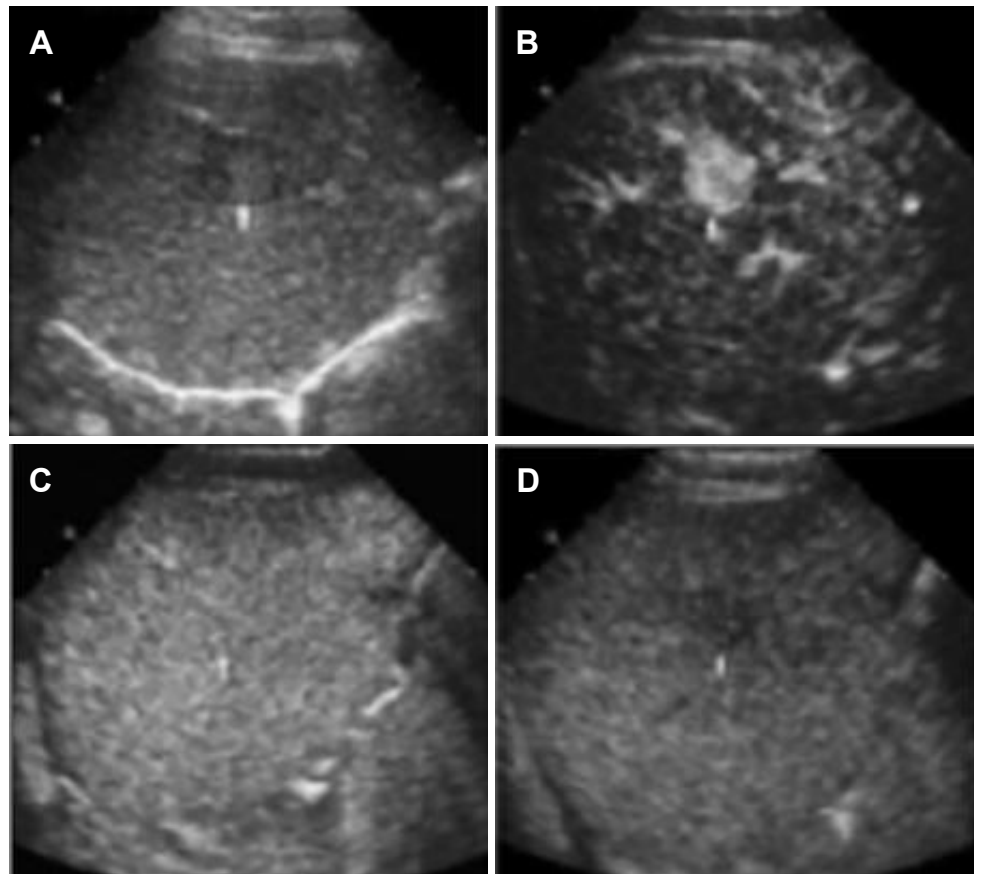

Figure 1. A: US shows a hypoechoic hepatocellular carcinoma (HCC); B: arterial phase (19 s) shows a homogeneous hyper-enhancement of the lesion; C: portal phase image ( $82 \mathrm{~s}$ ): the nodule is isoechoic; D: late portal phase $(190 \mathrm{~s})$ : the HCC is slightly hypoechoic with respect to surrounding liver
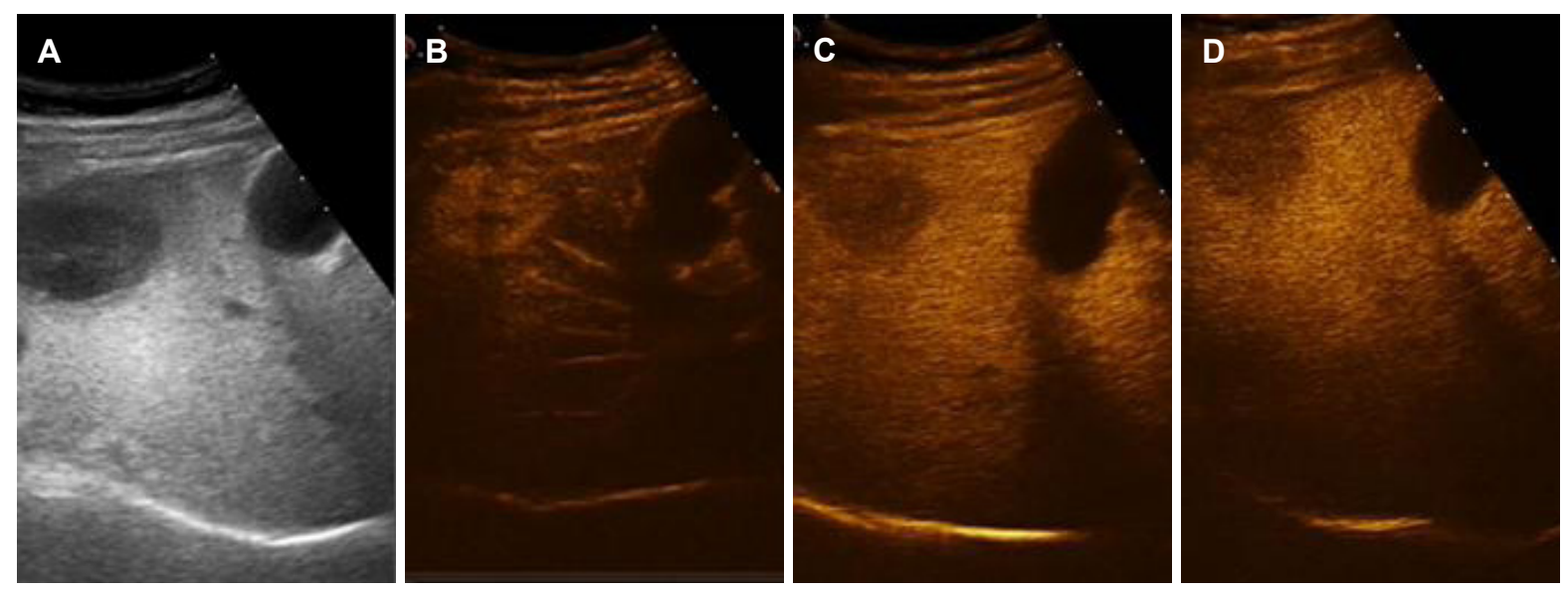

Figure 2. A: US shows a hypoechoic hepatocellular carcinoma $(\mathrm{HCC})(>2 \mathrm{~cm})$; $\mathrm{B}$ : arterial phase $(26 \mathrm{~s})$ shows an inhomogeneous hyperenhancement of the lesion; C: portal phase image (70 s) shows wash-out of contrast medium; D: late phase image (95 s): the HCC is hypoechoic with respect to surrounding liver

To increase the specificity of CEUS on the basis of these findings, a demonstration of the washout-phase is decisive and its presence also depends on the size of the nodule: the wash-out is described only in $20 \%-30 \%$ of nodules with diameters of $1-2 \mathrm{~cm}$ and in $40 \%-60 \%$ of nodules with diameters of $2-3 \mathrm{~cm}^{[22,38,42-59]}$.

The speed of the wash-out can define the level of differentiation of HCC: poorly differentiated show rapid wash-out, while the well differentiated HCC tends to be iso- or hypo-enhanced compared to parenchyma in the portal or late venous phase $\mathrm{e}^{[21,31,60-62]}$ [Figure 4]. 
Table 1. Typical enhancement of hepatocellular carcinoma in the arterial phase based on the size of lesion

\begin{tabular}{lc}
\hline Size lesion $\mathbf{( c m )}$ rate of detection of the hyper-enhancement in lesion \\
\hline$<1.0 \mathrm{~cm}$ & $67 \%$ \\
$1-2 \mathrm{~cm}$ & $83 \%-88 \%$ \\
$2-3 \mathrm{~cm}$ & $92 \%-100 \%$ \\
\hline
\end{tabular}
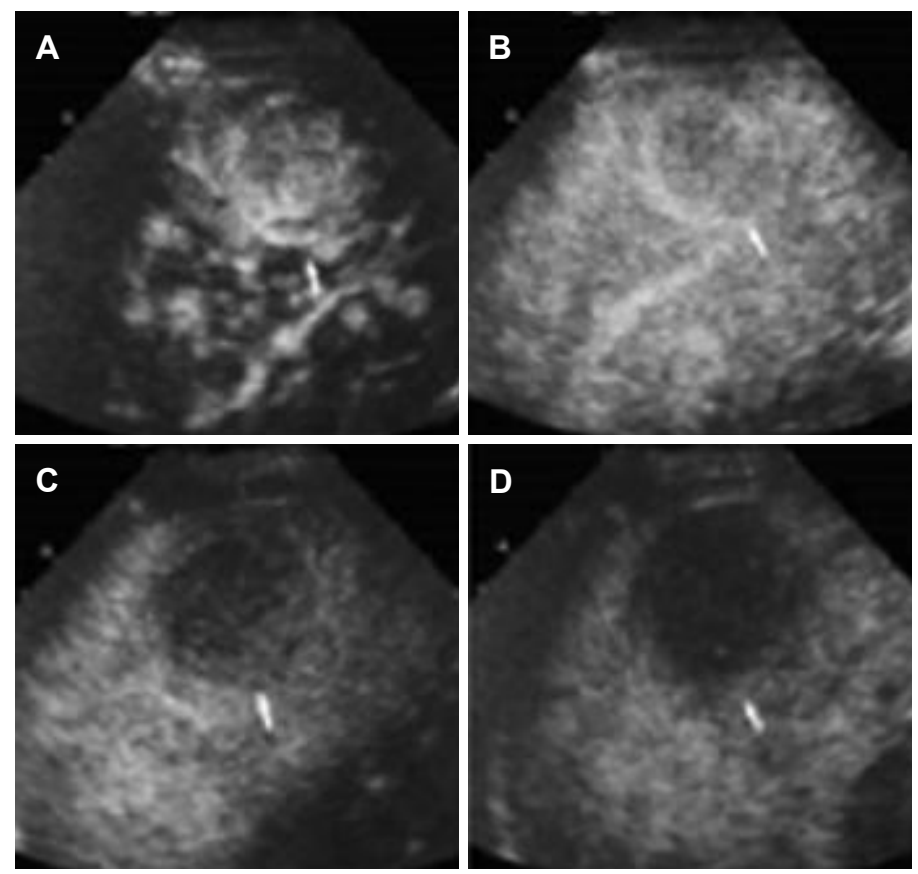

Figure 3. A: Arterial phase (18 s) shows a heterogeneous hyper-enhancement of the lesion; B: portal phase ( $32 \mathrm{~s}$ ): the nodule is slightly hypoechoic; C: portal phase (90 s): the nodule is hypoechoic; D: late portal phase (180 s): the nodule is remarkably hypoechoic with respect to the surrounding liver. Capsule of the lesion is well represented (arrows) more evident in $\mathrm{A}$ and $\mathrm{B}$

In order to increase the sensitivity of the diagnosis of HCC, in the cirrhotic liver it is useful to observe for more than $4 \mathrm{~min}$, in fact in these cases the wash-out tends to start later, generally not before $60 \mathrm{~s}$ after the injection, and in a quarter of cases it appears after only $180 \mathrm{~s}^{[40]}$. For this reason the presence of precocious wash-out $(<60 \mathrm{~s})$ has been described in HCC poorly differentiated and in cases of ICC ${ }^{[22,40,61-62]}$.

In conclusion, a hyper-enhancement in the arterial phase, followed by a washout in the late phase is a typical CEUS pattern in HCC in cirrhotic livers ${ }^{[63]}$. Usually regenerative/dysplastic nodule doesn't show this kind of pattern contrast enhancement that appears similar to the parenchyma.

\section{DISCUSSION}

In $90 \%$ of cases the development of hepatocarcinoma occurs through a multi-step path in which the lesion passes from a benign to a malignant lesion following an order summarized in Table 2. During this long process, a reduction in the normal arterial blood supply and the contemporary and progressive increase in newly formed tumor vessels (neo-angiogenesis) were detected. The development of second generation contrast-medium and specific imaging techniques with dedicated softwares, allows to observe the perfusion of the lesion in real time, becoming an useful and less invasive method, in describing precisely blood supply of nodule ${ }^{[3]]}$. However, in clinical practice, non invasive diagnosis of HCC is relatively recent. Until 2000 the diagnosis of HCC occurred through invasive biopic studies and successive histologic diagnosis ${ }^{[2]}$. 
Table 2. Development of hepatocellular carcinoma (HCC)
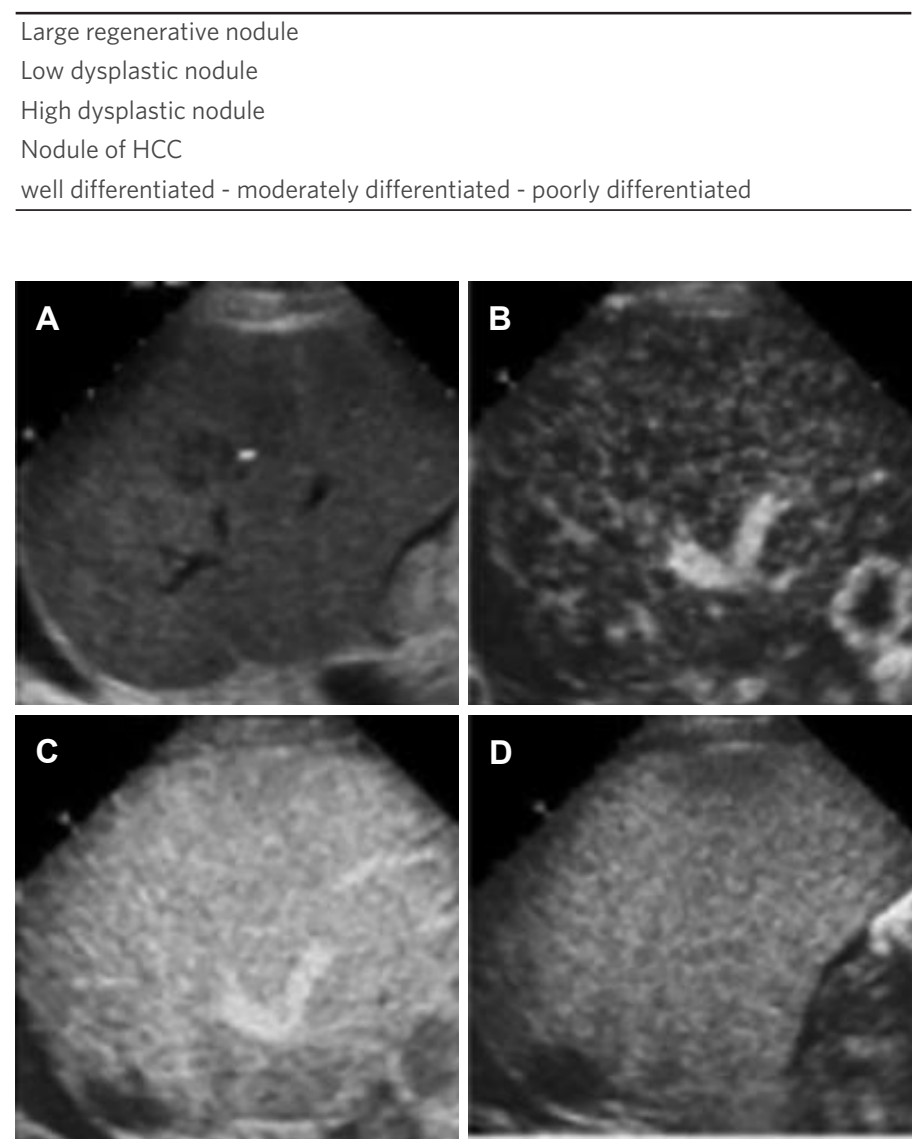

Figure 4. A: US shows a hypoechoic nodule; B: portal phase (32 s): arterial phase ( $23 \mathrm{~s}$ ) shows a homogeneous isoenhancement of the lesion; C: portal phase (52 s): the nodule is isoechoic with respect to the surrounding liver; D: late portal phase (280 s): the hepatocellular carcinoma $(\mathrm{HCC})$ is isoechoic with respect to the surrounding liver

In 2001 a group of experts European Association for the Study of the Liver (EASL) on HCC in Barcelona reported, for the first time, the criteria for a non invasive diagnosis ${ }^{[64]}$. These criteria required only the presence of a certain dynamic contrast enhancing behavior: the uptake of a contrast medium during the arterial phase documented through CT, angiography magnetic resonance imaging (MRI) or US. Therefore, in a cirrhotic liver, were considered HCC the nodule lesions with a diameter bigger than $2 \mathrm{~cm}$ that showed this uptake of contrast medium in 2 different imaging modalities or showed this contrast enhancing impregnation in a single imaging modality but with serum levels of AFP bigger than $400 \mathrm{ng} / \mathrm{mL}$. In all other cases a biopsy was neces$\operatorname{sary}^{[22,64]}$.

In 2005 EASL and American Association for the Study of Liver Diseases (AASLD) reached a new radiological signal to further distinguish HCC: wash-out in the venous/late phase $\mathrm{e}^{[5,22]}$. So the non invasive diagnosis of HCC was based both on the presence of uptake of the contrast medium in the arterial phase and on the wash-out in the venous/late phase. For nodules larger than $2 \mathrm{~cm}$ these radiological criteria should have been present in just one imaging modality; for nodules of the dimensions of $1-2 \mathrm{~cm}$ these radiological signs should have been shown in at least two imaging modalities (CT, MRI and CEUS). The AFP was eliminated from the diagnostic algorithm due to some limitations ${ }^{[5,22]}$. Due to the ability to visualize in real time the perfusion of hepatic lesions, CEUS can have a foremost role in the diagnosis of HCC; however it is currently accepted in variable ways in national and international guidelines. At the moment, CEUS is recommended by European Federation of Societies for Ultrasound in Medicine and Biology (EFSUMB) and is part of the Japanese guide- 
Table 3. Recommendations of European Federation of Societies for Ultrasound in Medicine and Biology for the use of contrast-enhanced ultrasoud

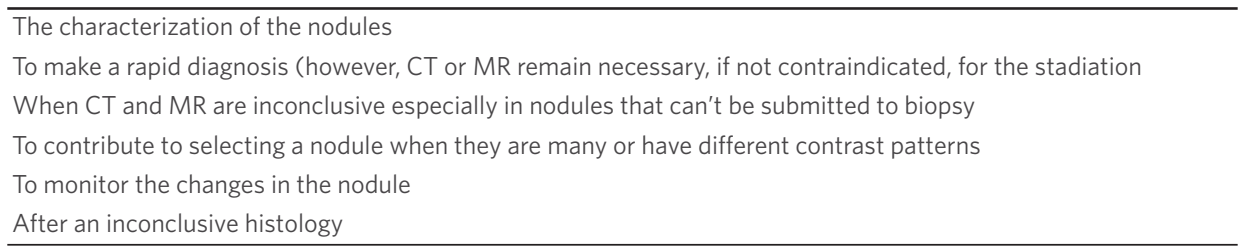

lines for $\mathrm{HCC}^{[22,23,65,66]}$, but it has been removed from American and EASL guidelines ${ }^{[48,53]}$. The main reason for this exclusion lies in the possibility of a mistaken diagnosis between ICC and HCC using only CEUS ${ }^{[67,68]}$. Furthermore this exclusion from AASLD guidelines is also related to the fact that, in the United States, contrast enhancing agents are not authorized for the study of the liver and so CEUS is not available. However, in clinical practice, the probability of mistaken diagnosis is minimal when CEUS is carried out by an expert physician ${ }^{[69]}$, because the ICC shows a rapid wash-out. Apart from this, in recent years a significant variability has been described, that has made the use of CEUS still more controversial ${ }^{[69]}$. In 2010 AASLD recommended that, for nodules bigger than $1 \mathrm{~cm}$, the non invasive diagnosis for HCC can be determined with a single means of imaging (CT multidetector or MRI with dynamic contrast $)^{[53]}$, if the typical contrast enhancement pattern is present; however when typical radiological aspects are not present and the behavior of the nodule is not characteristic, it is necessary to evaluate the nodule through a second imaging technique or with a biopsy ${ }^{[53]}$. This change is based on the conclusion of several studies that have demonstrated that the use of a single contrast technique causes a reduction in the positive predictive value that remains higher than $90 \%{ }^{[42,59]}$, they highlight a higher specificity than the typical radiological $\operatorname{sigh}^{[41,70]}$. AASLD guidelines suggest the necessity of adhering closely to imaging protocol and carrying out non invasive diagnosis of HCC in expert centers ${ }^{[2,53]}$.

Recent EASL guidelines are similar to those of AASLD, suggesting the use of multiphase imaging CT and up to date MRI for non invasive diagnosis of $\mathrm{HCC}^{[48]}$; in particular for nodules between $1-2 \mathrm{~cm}$, a single imaging technique is advised when carried out exclusively in excellent centers and with high grade radiological equipment or 2 imaging techniques when these criteria are not present and are carried out in inferior contexts. Such prudent recommendations of EASL guidelines are based on evidence of equivocal data concerning non invasive diagnosis of nodules $1-2 \mathrm{~cm}^{[22,48,53]}$. EFSUMB suggests a very different role for CEUS, describing it separately in two patients subgroups, with and without cirrhosis; this because of the great difference between types of hepatic nodules in cirrhotic and non cirrhotic livers ${ }^{[22-23]}$. In cirrhotic livers, among the recommendations of EFSUMB for the use of CEUS ${ }^{[23]}$ are summarized in Table 3. The multicenter German Society for Ultrasound in Medicine (DEGUM) included 1349 patients with FLLs diagnosed on US; CEUS was compared to the biopsy in $75 \%$ of cases and in $25 \%$ with contrast enhancement (CE) CT or CE-MRI. The accuracy of CEUS was $90.3 \%{ }^{[71-75]}$.

Another two DEGUM studies evaluated the capacity of CEUS in the characterization of FLL, comparing CEUS in the first study with CE-CT and in the second with CE-MR. In both cases there were no statistically significant differences ${ }^{[75-77]}$. In 2012, Goto et al. ${ }^{[78]}$ reported a major sensibility and sensitivity of baseline US in comparison with CEUS, using Sonazoid, in the detection of HCC during the post-vascular phase. In the differential diagnosis between HCC and ICC there is some controversy about the role of washout: in the late phase the wash-out of HCC seems to be less marked than the other liver neoplasms like ICC and metastasis ${ }^{[23,38,69,79]}$. Reanalyzing the data of the studies, Guo and $\mathrm{Xu}^{\left[{ }^{[80]}\right.}$, found that the clinical consequences that come from this risk do not seem to justify the complete removal of CEUS as an imaging technique in the characterization of FLL. With regard to this, further positive evidence is being gathered: Li et al. ${ }^{[81]}$ evaluated in the first place the usefulness of CEUS in differentiating ICC from HCC in cirrhotic patients through a detailed analysis of the characteristics of temporal enhancement. Therefore, in a cirrhotic liver if a nodule shows a hyper-enhancement 
in the arterial phase followed by a precocious and marked washout in the portal phase, the nodule is highly suspected of ICC; HCC, however, shows a moderate washout in the portal phase and, sometimes, can show iso-enhancing compared to surrounding parenchyma. These results have provided the last evidence to reprove the opinion of $\operatorname{AASLD}^{[80]}$.

The meta-analysis with evidence from 1998 to 2016 of Zhang et al. ${ }^{[82]}$ showed that CEUS was a useful diagnostic instrument for distinguishing HCC from other FLLs and, in conclusion, could also become a front line imaging instrument in the future. Masuzaky et al ${ }^{[83]}$ and Chan et al ${ }^{[84]}$ reported that CEUS has an important role in patient candidates to the treatment with radiofrequency ablation (RFA), increasing the detection of HCC that are not seen or poor seen on B-mode US and provides real-time guidance of RFA with good shortterm treatment responses. Intrinsic limitations of CEUS vary in relation to patient characteristics (cooperation, obesity, meteorism), characteristics of lesion (site-dimesions-depth) and the CEUS experienced operator.

Another important limitation of CEUS compared to cross sectional image formation is that only one FLL can be evaluated at a time and the repeated administration in bolus of SonoVue is necessary to evaluate other FLLs. However, in clinical practice, only 2 and 3 FLLs situated in the same segment lobe can be simultaneously and easily examined with CEUS ${ }^{[85]}$. On CEUS, the evaluation of enhancement is statistically significant in relation to the depth; in particular, at a depth greater than $9 \mathrm{~cm}$ from abdominal wall, only $58 \%$ of FLL present the same arterial enhancement compared to the corresponding phase in multi-slice CT; this contrasts with $95 \%$ of the lesions situated more superficially ${ }^{[86]}$.

Some studies have demonstrated that a number of lesions, varying 5\%-25\%, remain unterminated after CEUS, because they do not present a characteristic pattern ${ }^{[86]}$. Contrast-enhancing agents until today have not demonstrated cardio-, hepatic- or nephro-toxic effects. It is not necessary to carry out laboratory tests to evaluate hepatic or renal function before their administration. There is limited data about use during pregnancy, breastfeeding or in pediatrics. In a retrospective study ${ }^{[87]}$ of 23,188 investigations with SonoVue the rate of serious adverse events was only $0.0086 \%$ (29 cases), including a pseudo- anaphylactic shock and a bronchospasm, but there were no fatalities.

\section{CONCLUSION}

CEUS is a non invasive, rapid, economical and accurate method for the diagnosis and management of HCC in cirrhotic patients; moreover it is repeatable, less stressful and less invasive for the patients and doesn't require exposure to radiation. CEUS is not nephro-toxic and is non allergenic. When the nodular lesions are controlled in the cirrhotic liver, CEUS allows a rapid characterization with good precision when carried out by a medical expert.

\section{DECLARATIONS}

\section{Authors' contributions}

Designed the work, collection and data analysis, critical revision of the article and final approval of the version to be published: Loria F, Parlati A, Loria G

Contributed to the execution of the ultrasound examination and to the interpretation of the results and to the bibliographic research: Loria F, Parlati A, Loria G, Frosina L, Crea G, Basile S, Alessio C, Di Leo G, De Caridi A, Maschio V, Zizzi N, Trapuzzano O, Galea SG

Contribuited also to revision of the article: Loria F, Parlati A, Loria G, Frosina L, Crea G, Basile S, Alessio C, Di Leo G, De Caridi A

Contributed also to drafting the article: Loria F, Parlati A, Loria G, Maschio V, Zizzi N, Trapuzzano O, Galea SG 


\section{Availability of data and materials}

Not applicable.

\section{Financial support and sponsorship}

None.

\section{Conflicts of interest}

All authors declared that there are no conflicts of interest.

\section{Ethical approval and consent to participate}

Not applicable.

\section{Consent for publication}

Not applicable.

\section{Copyright}

(c) The Author(s) 2018.

\section{REFERENCES}

1. Albrecht T, Blomley M, Bolondi L, Claudon M, Correas JM, Cosgrove D, Greiner L, Jäger K, Jong ND, Leen E, Lencioni R, Lindsell D, Martegani A, Solbiati L, Thorelius L, Tranquart F, Weskott HP, Whittingham T; EFSUMB Study Group. Guidlines for the use of contrast agents in ultrasound. Ultraschall Med 2004;25:249-56.

2. Amano S, Ebara M, Yajima T, Fukuda H, Yoshikawa M, Sugiura N, Kato K, Kondo F, Matsumoto T, Saisho H. Assessment of cancer cell differentiation in small hepatocellular carcinoma by computed tomography and magnetic resonance imaging. J Gastroenterol Hepatol 2003;18:273-9.

3. Bolondi L, Gaiani S, Celli N, Golfieri R, Grigioni WF, Leoni S, Venturi AM, Piscaglia F. Characterization of small nodules in cirrhosis by assessment of vascularity: the problem of hypovascular hepatocellular carcinoma. Hepatology 2005;42:27-34.

4. Brannigan M, Burns PN, Wilson SR. Blood flow patterns in focal liver lesions at microbubble-enanched US. Radiographics 2004;24:92135 .

5. Bruix J, Sherman M. Management of hepatocellular carcinoma. Hepatology 2005;42:1208-36.

6. Bota S, Piscaglia F, Marinelli S, Pecorelli A, Terzi E, Bolondi L. Comparison of international guidelines for noninvasive diagnosis of hepatocellular carcinoma. Liver Cancer 2012;1:190-200.

7. Chen RC, Wang CK, Wang CS, Chen WT, Shih LS, Chiang LC, Chen PH. Depiction of vasculature in small hepatocellular carcinoma, and dysplastic nodules evaluated with carbon dioxide ultrasonography and angiography. Acta Radiol 2002;43:66-70.

8. Chhieng DC. Fine needle aspiration biopsy of liver-an update. World J Surg Oncol 2004;2:5-15.

9. Choi BI, Takayasu K, Han MC. Small hepatocellular carcinomas and associated nodular lesions of the liver: pathology, pathogenesis, and imaging findings. AJR Am J Roentgenol 1993;160:1177-87.

10. Edmondson HA, Steiner PE. Primary carcinoma of the liver: a study of 100 cases among 48,900 necropsies. Cancer 1954;7:462-503.

11. Gaiani S, Casali A, Serra C, Piscaglia F, Gramantieri L, Volpe L, Siringo S, Bolondi L. Assessment of vascular patterns of small liver mass lesions: value and limitation of the different Doppler ultrasound modalities. Am J Gastroenterol 2000;95:3537-46.

12. Hayashi M, Matsui O, Ueda K, Kawamori Y, Gabata T, Kadoya M. Progression to hypervascular hepatocellular carcinoma: correlation with intranodular blood supply evacuate with CT during intraarterial injection of contrast material. Radiology 2002;225:143-9.

13. Honda H, Tajima T, Kajiyama K, Kuroiwa T, Yoshimitsu K, Irie H, Aibe H, Shimada M, Masuda K. Vascular changes in hepatocellular carcinoma: correlation of radiologic and pathologic findings. AJR Am J Roentgenol 1999;173:1213-17.

14. Honda H, Tajima T, Taguchi K, Kuroiwa T, Yoshimitsu K, Irie H, Aibe H, Shinozaki K, Asayama Y, Shimada M, Masuda K. Recent developments in imaging diagnostics for HCC: CT arteriography and CT arteriopotography evaluation of vascular changes in premalignant and malignant hepatic nodules. J Hepatobiliary Pancreat Surg 2000;7:245-51.

15. Hussain SM, Zondervan PE, IJzermans JN, Schalm SW, de Man RA, Krestin GP. Bening versus malignant hepatic nodules: MR imaging findings with pathologic correlation. Radiographics 2002;22:1023-39.

16. Kudo M, Tomita S, Tochio H, Mimura J, Okabe Y, Kashida H, Hirasa M, Ibuki Y, Todo A. Sonography with intaarterial infusion of carbon dioxide microbubbles (sonographic angiography): value in differential diagnosis of hepatic tumors. AJR Am J Roentgenol 1992;158:65-74.

17. Kumada T, Nakano S, Toyoda H, Hayashi K, Kiriyama S, Sone Y, Tanikawa M, Hisanaga Y, Yamamoto A, Takeshima K, Hibi T, Yabashi T, Noda T, Sassa T, Furukawa M, Ogawa S. Assessment of tumor hemodynamics in small hepatocellular carcinoma: comparison of Doppler ultrasonography, angiography-assisted computed tomography, and pathological findings. Liver Int 2004;24:425-31.

18. Lencioni R, Pinto F, Armillotta N, Bartolozzi C. Assessment of tumor vascularity in hepatocellular carcinoma: comparison of power Doppler US and color Doppler US. Radiology 1996;201:353-8.

19. Matsui O, Kadoya M, Kameyama T, Yoshikawa J, Takashima T, Nakanuma Y Unoura M, Kobayashi K, Izumi R, Ida M. Bening and 
malignant nodules in cirrhotic livers: distinction based on blood supply. Radiology 1991;178:493-7.

20. Ng IO. Prognostic significance of pathological and biological factors in hepatocellular carcinoma. J Gastroenterol Hepatol 1998;13:666-70.

21. Nicolau C, Catalá V, Vilana R, Gilabert R, Bianchi L, Solé M, Pagés M, Brú C. Evaluation of hepatocellular using SonoVue, a second generation ultrasound contrast agent: correlation with cellular differentiation. Eur Radiol 2004;14:1092-9.

22. Serra C, Righi S, Molo CD, Felicani C. Current role of contrast-enhanced ultrasound in the diagnosis of hepatocellular carcinoma. J Hepatol Gastroint Dis 2015;1:102.

23. Claudon M, Dietrich CF, Choi BI, Cosgrove DO, Kudo M, Nolsøe CP, Piscaglia F, Wilson SR, Barr RG, Chammas MC, Chaubal NG, Chen MH, Clevert DA, Correas JM, Ding H, Forsberg F, Fowlkes JB, Gibson RN, Goldberg BB, Lassau N, Leen EL, Mattrey RF, Moriyasu F, Solbiati L, Weskott HP, Xu HX; World Federation for Ultrasound in Medicine; European Federation of Societies for Ultrasound. Guidelines and good clinical practice recommendations for Contrast Enhanced Ultrasound (CEUS) in the liver - update 2012. A WFUMB-EFSUMB initiative in cooperation with representatives of AFSUMB, AIUM, ASUM, FLAUS and ICUS. Ultrasound Med Biol 2013;39:187-210.

24. Cosgrove D, Harvey C. Clinical uses of microbubbles in diagnosis and treatment. Med Biol Eng Comput 2009;47:813-26.

25. Claudon M, Cosgrove D, Albrecht T, Bolondi L, Bosio M, Calliada F, Correas JM, Darge K, Dietrich C, D’Onofrio M, Evans DH, Filice C, Greiner L, Jäger K, Jong Nd, Leen E, Lencioni R, Lindsell D, Martegani A, Meairs S, Nolsøe C, Piscaglia F, Ricci P, Seidel G, Skjoldbye B, Solbiati L, Thorelius L, Tranquart F, Weskott HP, Whittingham T. Guidelines and good clinical practice recommendations for contrast enhanced ultrasound (CEUS) - update 2008. Ultraschall Med 2008;29:28-44.

26. Simpson DH, Chin CT, Burns PN. Pulse inversion Doppler: a new method for detecting nonlinear echoes from microbubble contrast agents. IEEE Trans on Ultrason, Ferroelectr, and Freq Control 1999;46:372-82..

27. Tiemann K, Lohmeier S, Kuntz S, Köster J, Pohl C, Burns P, R T, Nanda NC, Lüderitz B, Becher H. Real-time contrast echo assessment of myocardial perfusion at low emission power: first experimental and clinical results using power pulse inversion imaging. Echocardiography 1999;16:799-809.

28. Averkiou M, Powers J, Skyba D, Bruce M, Jensen S. Ultrasound contrast imaging research. Ultrasound Q 2003;19:27-37.

29. Szabo T. Diagnostic ultrasound imaging. Amsterdam: Academic Press; 2004.

30. Dietrich CF, Ignee A, Hocke M, Schreiber-Dietrich D, Greis C. Pitfalls and artefacts using contrast enhanced ultrasound. Z Gastroenterol 2011;49:350-6.

31. Loria F, Loria G, Basile S, Crea G, Randazzo D, Frosina L. Contrast-enhanced ultrasound of hepatocellular carcinoma: correlation between enhancement pattern and cellular differentiation on histopathlogy. Updates Surg 2012;64:247-55.

32. Murakami T, Tsurusaki M, Hyodo T, Imai Y. Clinical utility of imaging for evaluation of hepatocellular carcinoma. J Hepatocell Carcinoma 2014;1:101-8

33. Gaiani S, Volpe L, Piscaglia F, Bolondi L. Vascularity of liver tumours and recent advances in doppler ultrasound. J Hepatol 2001;34:47482.

34. Xu HX, Liu GJ, Lu MD, Xie XY, Xu ZF, Zheng YL, Liang JY. Characterization of small focal liver lesions using real-time contrast-enhanced sonography: diagnostic performance analysis in 200 patients. J Ultrasound Med 2006;25:349-61.

35. Xu HX, Liu GJ, Lu MD, Xie XY, Xu ZF, Zheng YL, Liang JY. Characterization of focal liver lesions using contrast-enhanced sonography with a low mechanical index mode and a sulfur hexafluoride-filled microbubble contrast agent. J Clin Ultrasound 2006;34:261-72.

36. Xu HX, Xie XY, Lu MD, Liu GJ, Xu ZF, Zheng YL, Liang JY, Chen LD. Contrast-enhanced sonography in the diagnosis of small hepatocellular carcinoma $<$ or $=2 \mathrm{~cm}$. J Clin Ultrasound 2008;36:257-66.

37. Quaia E, Calliada F, Bertolotto M, Rossi S, Garioni L, Rosa L, Pozzi-Mucelli R. Characterization of focal liver lesions with contrast-specific US modes and a sulfur hexafluoride-filled microbubble contrast agent: diagnostic performance and confidence. Radiology 2004;232:420-30.

38. Zheng SG, Xu HX, Liu LN. Management of hepatocellular carcinoma: the role of contrast-enhanced ultrasound. World J Radiol 2014;6:714

39. Gaiani S, Celli N, Piscaglia F, Cecilioni L, Losinno F, Giangregorio F, Mancini M, Pini P, Fornari F, Bolondi L. Usefulness of contrastenhanced perfusional sonography in the assessment of hepatocellular carcinoma hypervascular at spiral computed tomography. J Hepatol 2004;41:421-6.

40. Chen MH, Dai Y, Yan K, Fan ZH, Yin SS, Yang W, Wu W, Wang YB, Li JY. The role of contrast-enhanced ultrasound on the diagnosis of small hepatocellular carcinoma $(</=3 \mathrm{~cm})$ in patients with cirrhosis. Hepatol Res 2006;35:281-8.

41. Sangiovanni A, Manini MA, Iavarone M, Romeo R, Forzenigo LV, Fraquelli M, Massironi S, Della Corte C, Ronchi G, Rumi MG, Biondetti $\mathrm{P}$, Colombo $\mathrm{M}$. The diagnostic and economic impact of contrast imaging techniques in the diagnosis of small hepatocellular carcinoma in cirrhosis. Gut 2010;59:638-44.

42. Leoni S, Piscaglia F, Golfieri R, Camaggi V, Vidili G, Pini P, Bolondi L. The impact of vascular and nonvascular findings on the noninvasive diagnosis of small hepatocellular carcinoma based on the EASL and AASLD criteria. Am J Gastroenterol 2010;105:599-609.

43. International Agency for Research Cancer. GLOBOCAN 2012: estimated cancer incidence, mortality and prevalence worldwide in 2012. Available from: http://globocan.iarc.fr/Pages/fact_sheets_population.aspx. [Last accessed on 14 Sep 2018]

44. Parkin DM, Bray F, Ferlay J, Pisani P. Global cancer statistics, 2002. CA Cancer J Clin 2005;55:74-108.

45. Sangiovanni A, Prati GM, Fasani P, Ronchi G, Romeo R, Manini M, Del Ninno E, Morabito A, Colombo M. The natural history of compensated cirrhosis due to hepatitis C virus: a 17- year cohort study of 214 patients. Hepatology 2006;43:1303-10.

46. Ioannou GN, Splan MF, Weiss NS, McDonald GB, Beretta L, Lee SP. Incidence and predictors of hepatocellular carcinoma in patients with cirrhosis. Clin Gastroenterol Hepatol 2007;5:938-45.

47. Raimondi S, Bruno S, Mondelli MU, Maisonneuve P. Hepatitis C virus genotype $1 \mathrm{~b}$ as a risk factor for hepatocellular carcinoma development: a meta-analysis. J Hepatol 2009;50:1142-54.

48. European Association for the Study of the Liver. European organisation for research and treatment of cancer. EASL-EORTC clinical practice guidelines: management of hepatocellular carcinoma. J Hepatol 2012;56:908-43. 
49. Kim CK, Lim JH, Lee WJ. Detection of hepatocellular carcinomas and dysplastic nodules in cirrhotic liver: accuracy of ultrasonography in transplant patients. J Ultrasound Med 2001;20:99-104

50. Bolondi L. Screening for hepatocellular carcinoma in cirrhosis. J Hepatol 2003;39:1076-84.

51. Singal A, Volk ML, Waljee A, Salgia R, Higgins P, Rogers MA, Marrero JA. Metaanalysis: surveillance with ultrasound for early-stage hepatocellular carcinoma in patients with cirrhosis. Aliment Pharmacol Ther 2009;30:37-47.

52. Lencioni R, Piscaglia F, Bolondi L. Contrast-enhanced ultrasound in the diagnosis of hepatocellular carcinoma. J Hepatol 2008;48:848-57.

53. Bruix J, Sherman M; American Association for the Study of Liver Diseases. Management of hepatocellular carcinoma: an update. Hepatology 2011;53:1020-2.

54. Lok AS, Sterling RK, Everhart JE, Wright EC, Hoefs JC, Di Bisceglie AM, Morgan TR, Kim HY, Lee WM, Bonkovsky HL, Dienstag JL; HALT-C Trial Group. Des-gamma-carboxy prothrombin and alpha-fetoprotein as biomarkers for the early detection of hepatocellular carcinoma. Gastroenterology 2010;138:493-502.

55. Zhang B, Yang B. Combined alpha fetoprotein testing and ultrasonography as a screening test for primary liver cancer. J Med Screen 1999;6:108-10.

56. Andersson KL, Salomon JA, Goldie SJ, Chung RT. Cost effectiveness of alternative surveillance strategies for hepatocellular carcinoma in patients with cirrhosis. Clin Gastroenterol Hepatol 2008;6:1418-24.

57. Makuuchi M, Kokudo N, Arii S, Futagawa S, Kaneko S, Kawasaki S, Matsuyama Y, Okazaki M, Okita K, Omata M, Saida Y, Takayama T, Yamaoka Y. Development of evidence-based clinical guidelines for the diagnosis and treatment of hepatocellular carcinoma in Japan. Hepatol Res 2008;38:37-51.

58. Nouso K, Tanaka H, Uematsu S, Shiraga K, Okamoto R, Onishi H, Nakamura S, Kobayashi Y, Araki Y, Aoki N, Shiratori Y. Costeffectiveness of the surveillance program of hepatocellular carcinoma depends on the medical circumstances. J Gastroenterol Hepatol 2008;23:437-44.

59. Forner A, Vilana R, Ayuso C, Bianchi L, Solé M, Ayuso JR, Boix L, Sala M, Varela M, Llovet JM, Brú C, Bruix J. Diagnosis of hepatic nodules $20 \mathrm{~mm}$ or smaller in cirrhosis: prospective validation of the noninvasive diagnostic criteria for hepatocellular carcinoma. Hepatology 2008;47:97-104.

60. Jang HJ, Kim TK, Burns PN, Wilson SR. Enhancement patterns of hepatocellular carcinoma at contrast-enhanced US: comparison with histologic differentiation. Radiology 2007; 244:898-906.

61. Boozari B, Soudah B, Rifai K, Schneidewind S, Vogel A, Hecker H, Hahn A, Schlue J, Dietrich CF, Bahr MJ, Kubicka S, Manns MP, Gebel M. Grading of hypervascular hepatocellular carcinoma using late phase of contrast enhanced sonography-a prospective study. Dig Liver Dis 2011;43:484-90.

62. Jang HJ, Kim TK, Burns PN, Wilson SR. Enhancement patterns of hepatocellular carcinoma at contrast-enhanced US: comparison with histologic differentiation. Radiology 2007;244:898-906.

63. International Consensus Group for Hepatocellular Neoplasia; The International Consensus Group for Hepatocellular Neoplasia. Pathologic diagnosis of early hepatocellular carcinoma: a report of the international consensus group for hepatocellular neoplasia. Hepatology 2009;49:658-64.

64. Bruix J, Sherman M, Llovet JM, Beaugrand M, Lencioni R, Burroughs AK, Christensen E, Pagliaro L, Colombo M, Rodés J; EASL Panel of Experts on HCC. Clinical management of hepatocellular carcinoma. Conclusions of the Barcelona-2000 EASL conference. European Association for the Study of the Liver. J Hepatol 2001;35:421-30.

65. Kudo M, Izumi N, Kokudo N, Matsui O, Sakamoto M, Nakashima O, Kojiro M, Makuuchi M; HCC Expert Panel of Japan Society of Hepatology. Management of hepatocellular carcinoma in Japan: Consensus-Based Clinical Practice Guidelines proposed by the Japan Society of Hepatology (JSH) 2010 updated version. Dig Dis 2011;29:339-64.

66. Kudo M, Okanoue T; Japan Society of Hepatology. Management of hepatocellular carcinoma in Japan: consensus-based clinical practice manual proposed by the Japan Society of Hepatology. Oncology 2007;1:2-15.

67. Vilana R, Forner A, Bianchi L, García-Criado A, Rimola J, de Lope CR, Reig M, Ayuso C, Brú C, Bruix J. Intrahepatic peripheral cholangiocarcinoma in cirrhosis patients may display a vascular pattern similar to hepatocellular carcinoma on contrast-enhanced ultrasound. Hepatology 2010;51:2020-9.

68. Rimola J, Forner A, Reig M, Vilana R, de Lope CR, Ayuso C, Bruix J. (2009) Cholangiocarcinoma in cirrhosis: absence of contrast washout in delayed phases by magnetic resonance imaging avoids misdiagnosis of hepatocellular carcinoma. Hepatology 2009;50:791-8.

69. Barreiros AP, Piscaglia F, Dietrich CF. Contrast enhanced ultrasound for the diagnosis of hepatocellular carcinoma (HCC): comments on AASLD guidelines. J Hepatol 2012;57:930-2.

70. Khalili K, Kim TY, Jang HJ, Haider MA, Guindi M, Sherman M. Implementation of AASLD hepatocellular carcinoma practice guideline in nothamerica: two years of experience. Meeting of the 2008;362A-362A.

71. Yu NC, Chaudhari V, Raman SS, Lassman C, Tong MJ, Busuttil RW, Lu DS. CT and MRI improve detection of hepatocellular carcinoma, compared with ultrasound alone, in patients with cirrhosis. Clin Gastroenterol Hepatol 2011;9:161-7.

72. Sersté T, Barrau V, Ozenne V, Vullierme MP, Bedossa P, Farges O, Valla DC, Vilgrain V, Paradis V, Degos F. Accuracy and disagreement of computed tomography and magnetic resonance imaging for the diagnosis of small hepatocellular carcinoma and dysplastic nodules: role of biopsy. Hepatology 2012;55:800-6.

73. Strobel D, Seitz K, Blank W, Schuler A, Dietrich C, von Herbay A, Friedrich-Rust M, Kunze G, Becker D, Will U, Kratzer W, Albert FW, Pachmann C, Dirks K, Strunk H, Greis C, Bernatik T. Contrast-enhanced ultrasound for the characterization of focal liver lesions-diagnostic accuracy in clinical practice (DEGUM multi center trial). Ultraschall Med 2008;29:499-505.

74. Strobel D, Seitz K, Blank W, Schuler A, Dietrich CF, von Herbay A, Friedrich-Rust M, Bernatik T. Tumor-specific vascularixation pattern of liver metastasis, hepatocellular carcinoma, emangioma and focal nodular hyperplasia in the differential diagnosis of 1349 liver lesions in contrast-enhanced ultrasound (CEUS). Ultraschall Med 2009;30:376-82.

75. Loria F. Vascolarizzazione dell' epatocarcinoma: ruolo della CEUS e della TC multifasica. La radiologia medica 2014;1:961-7. 
76. Seitz K, Strobel D, Bernatik T, Blank W, Friedrich-Rust M, Herbay Av, Dietrich CF, Strunk H, Kratzer W, Schuler A. Contrast-enhanced ultrasound (CEUS) for the characterization of focal liver lesions-prospective comparison in clinical practice: CEUS vs. CT (DEGUM multicenter trial). Parts of this manuscript were presented at the Ultrasound Dreiländertreffen. Ultraschall Med 2009;30:383-9.

77. Seitz K, Bernatik T, Strobel D, Blank W, Friedrich-Rust M, Strunk H, Greis C, Kratzer W, Schuler A. Contrast-enhanced ultrasound (CEUS) for the characterization of focal liver lesions in clinical practice (DEGUM multicenter trial): CEUS vs MRI--a prospective comparison in 269 patients. Ultraschall Med 2010;31:492-9.

78. Goto E, Masuzaki R, Tateishi R, Kondo Y, Imamura J, Goto T, Ikeda H, Akahane M, Shiina S, Omata M, Yoshida H, Koike K. Value of post-vascular phase (Kupffer imaging) by contrast-enhanced ultrasonography using Sonazoid in the detection of hepatocellular carcinoma. J Gastroenterol 2012;47:477-85.

79. Xu HX, Lu MD, Liu GJ, Xie XY, Xu ZF, Zheng YL, Liang JY. Imaging of peripheral cholangiocarcinoma with low-mechanical index contrast-enhanced sonography and SonoVue: initial experience. J Ultrasound Med 2006;25:23-33.

80. Guo L-H, Xu H-X. Contrast-enhanced ultrasound in the diagnosis of hepatocellular carcinoma and intrahepatic cholangiocarcinoma: controversy over the ASSLD Guideline. Biomed Res Int 2015;2015:1-5.

81. Li R, Yuan MX, Ma KS, Li XW, Tang CL, Zhang XH, Guo DY, Yan XC. Detailed analysis of temporal features on contrast enhanced ultrasound may help differentiate intrahepatic cholangiocarcinoma from hepatocellular carcinoma in cirrhosis. PLoS One 2014; 9:e98612.

82. Zhang J, Yu Y, Li Y, Wei L. Diagnostic value of contrast-enhanced ultrasound in hepatocellular carcinoma: a meta-analysis with evidence from 1998 to 2016. Oncotarget 2017;8:75418-26.

83. Masuzaki R, Shiina S, Tateishi R, Yoshida H, Goto E, Sugioka Y, Kondo Y, Goto T, Ikeda H, Omata M, Koike K. Utility of contrastenhanced ultrasonography with Sonazoid in radiofrequency ablation for hepatocellular carcinoma. J Gastroenterol Hepatol 2011; 26:759-64.

84. Chan AK, Hegarty C, Klass D, Yoshida E, Chung S, Liu DM, Ho SG, Harris AC. The role of contrast-enhanced ultrasound in guiding radio frequency ablation of hepatocellular carcinoma: a retrospective study. Can Assoc Radiol J 2015;66:171-8.

85. Chiorean L, Tana C, Braden B, Caraiani C, Sparchez Z, Cui XW, Baum U, Dietrich CF. Advantages and limitations of focal liver lesion assessment with ultrasound contrast agents: comments on the European Federation of Societies for Ultrasound in Medicine and Biology (EFSUMB) Guidelines. Med Princ Pract 2016;25:399-407.

86. Loria F, Loria G, Basile S, Crea G, Frosina L, Frosina F. Role of contrast-enhanced ultrasound in the evaluation of vascularization of hepatocellular carcinoma. Hepatoma Research 2016;2:316-22.

87. Piscaglia F, Bolondi L; Italian Society for Ultrasound in Medicine and Biology (SIUMB) Study Group on Ultrasound Contrast Agents. The safety of SonoVue in abdominal applications: retrospective analysis of 23188 investigations. Ultrasound Med Biol 2006;32:1369-75. 